\title{
МЕЖДУНАРОДНО-ПРАВОВЫЕ ВОПРОСЫ ОТВЕТСТВЕННОСТИ МЕЖДУНАРОДНЫХ ФИНАНСОВЫХ ОРГАНИЗАЦИЙ ПО ВНУТРИГОСУДАРСТВЕННОМУ ЗАКОНОДАТЕЛЬСТВУ
}

\section{INTERNATIONAL LEGAL ISSUES OF RESPONSIBILITY OF INTERNATIONAL FINANCIAL ORGANIZATIONS UNDER DOMESTIC LAW}

\section{P. Chuvakhin}

Summary. The article is devoted to the analysis of international legal issues related to the consideration of disputes involving international financial organizations in national judicial institutions, as well as the problems of abuse of immunity by international financial organizations. The judicial immunities of international financial organizations should not be absolute, therefore, when considering disputes on holding international financial organizations liable in national courts, such immunities should be limited by fixing the obligation of the organization in certain cases to waive immunity, and also by recognizing abuse by the court organizations with their right to immunity.

Keywords: international financial organization, immunities of international financial organizations, responsibility of international financial organizations, disputes in national courts, labor disputes.
$\mathbf{M}$ еждународные финансовые организации для реализации своих уставных целей и обеспечения своей деятельности нередко становятся участниками частноправовых отношений, правовое регулирование которых осуществляется на уровне национального законодательства. Поэтому и ответственность таких организаций за неисполнение своих обязательств будет реализовываться на основе норм национального права. Однако, существенным препятствием для реализации данного вида ответственности является наличие у международных организаций иммунитетов.

В доктрине международного права в отношении государств традиционно выделяется три концепции иммунитета: концепция судебного иммунитета, то есть невозможность привлечения государства к участию в судебном производстве другого государства, концепция абсолютного иммунитета, согласно которой государство может привлекаться к участию в судебном процессе в другом государстве только при даче своего
Чувахин Петр Игоревич

Преподаватель, Финансовый университет при Правительстве РФ, г. Москва; старший преподаватель, Российский экономический университет им. Г.В. Плеханова, г. Москва chuvakhin.petr@yandex.ru

Аннотация. Статья посвящена анализу международно-правовых вопросов, связанных с рассмотрением споров с участием международными финансовыми организациями в национальных судебных учреждениях, а также проблемам злоупотребления международными финансовыми организациями своими иммунитетами. Судебные иммунитеты международных финансовых организаций не должны иметь абсолютный характер, поэтому, при рассмотрении споров о привлечении к ответственности международных финансовых организаций в национальных судах, такие иммунитеты должны ограничиваться путем закрепления обязанности организации в определенных случаях отказаться от иммунитета, а также путем признания судом злоупотребления со стороны организации своим правом на иммунитет.

Ключевые слова: международная финансовая организация, иммунитеты международных финансовых организаций, ответственность международных финансовых организаций, споры в национальных судах, трудовые споры.

согласия, концепция ограниченного или функционального иммунитета, согласно которой при осуществлении государством коммерческой деятельности частноправового характера, государство перестает пользоваться иммунитетом. В отношении международных организаций указанные концепции не применяются, в отечественной и зарубежной доктрине признается только функциональный иммунитет международных организаций. Его не следует отождествлять с функциональным иммунитетом государств, так как данные понятия имеют разную правовую природу.

Функциональный иммунитет международной организации обеспечивает ей защиту от:

- контроля со стороны других государств,

- контрольных механизмов государств, на территории которых расположены штаб-квартиры международной организации, в отношении материальных ресурсов организации,

- налогообложения в пользу бюджета конкретного государства и т.п. 
Кроме перечисленного, функциональный иммунитет может обеспечивать международной организации защиту от судебного разбирательства в национальных судах, а также защиту от принудительного исполнения судебных решений национальных судов и от принудительных мер по обеспечению иска.

Чтобы международная финансовая организация могла осуществлять свои цели в полном объеме, иммунитет необходим не только самой организации, но и ее должностным лицам. В большинстве учредительных актов международных организаций предусматривается наличие иммунитета у должностных лиц, включая иммунитеты членов органов управления организацией (например, членов Совета управляющих или Директора). Как правило, такие иммунитеты касаются неподчинения юрисдикции государств пребывания, освобождения от воинской обязанности, упрощения регистрации в качестве иностранцев, свободы перемещения и т.п. Как отмечает в своей работе С. Ю. Суменков, данный иммунитет примыкает и тесно связан с дипломатическим иммунитетом [1].

Объем иммунитета у международных организаций может отличаться в зависимости от того, как это будет указано в учредительных и иных актах разных организаций.

Так, основные положения об иммунитете Международного валютного фонда закреплены в его учредительном акте - Статьях Соглашения о Международном валютном фонде (статья 9) [2]. В десяти разделах указанной статьи помимо иммунитета рассматриваются также тесно с ним связанные понятия статуса и привилегий. Согласно разделу 2, Фонд обладает статусом юридического лица, вправе вступать в договорные обязательства, совершать сделки с имуществом, а также инициировать судебное разбирательство.

Раздел 3 посвящен судебному иммунитету, который предполагает, что Фонд, а также все его имущество и активы, независимо от местонахождения и иных обстоятельств, неподсудны никакому национальному суду. Исключением здесь является только случай, когда Фонд определенно отказался от своего иммунитета. По сути, данное положение повторяет концепцию абсолютного иммунитета государств. Четвертый раздел раскрывает иммунитет Фонда от иных действий, таких как обыск, реквизиция, конфискация, экспроприация и иные формы принудительного отчуждения в отношении имущества и активов Фонда. Разделы 5-7 посвящаются неприкосновенности архивов и сообщений Фонда. В разделе 8 описываются иммунитеты всех должностных лиц Фонда, а в разделе 9 раскрывается иммунитет Фонда от налогов, сборов и иных обязательных платежей.
Анализируя Статьи Соглашения Международного банка реконструкции и развития (статья 7), можно сделать вывод, что правовое регулирование иммунитетов и привилегий Банка содержательно и структурно совпадает с аналогичным регулированием в Международном валютном фонде [3]. Отличием является только регулирование судебного иммунитета. Так, в соответствующем разделе предусматривается, что Банк может участвовать в рассмотрении возбужденных против него дел, но только в национальных судах тех государств, где у Банка имеются соответствующее учреждение или где Банк выпускает и гарантирует ценные бумаги. Такое положение обуславливается тем, что Международный банк реконструкции и развития активно осуществляет финансирование в различные проекты на территориях государств-членов, и, как следствие, возможно возникновение споров с частными лицами этих государств, участвующих в проектах Банка. Поэтому чтобы у таких частных лиц была возможность защитить свои права, Банк устанавливает подобное изъятие из своего судебного иммунитета.

В целом, точно такие же положения содержатся в учредительных документах остальных организаций Группы Всемирного Банка - в Статьях Соглашения Международной ассоциации развития (статья 8), в Статьях Соглашения Международной финансовой корпорации (статья 8) [4], в Сеульской конвенции об учреждении Многостороннего агентства по гарантиям инвестиций (глава 7) [5] и в Вашингтонской конвенции о порядке разрешения инвестиционных споров между государствами и иностранными лицами (раздел 6 первой главы) [6]. Хотя в некоторых из перечисленных документов все же устанавливаются свои особенности регулирования иммунитетов. Например, в учредительных актах Международной финансовой корпорации и Многостороннего агентства по гарантиям инвестиций в отдельную статью выделено право данных организаций отказаться от любых привилегий и иммунитетов в любом объеме (раздел 11 статьи 8 и статья 50 соответственно), а в Вашингтонской конвенции Многосторонний центр по урегулированию инвестиционных споров наделяется всеми видами иммунитета, никак при этом не конкретизированных (статья 20).

Как уже отмечалось, положения об иммунитетах международных финансовых организаций содержатся также в многосторонних конвенциях. Примером такой конвенции может являться Конвенция о привилегиях и иммунитетах специализированных учреждений [7], к числу которых относятся такие международные финансовые организации, как Международный валютный фонд и Международный банк реконструкции и развития. Значение данной Конвенции заключается в том, что каждое государство, присоединяясь к ней, обязует- 
ся предоставлять специализированным учреждениям на своей территории все перечисленные Конвенцией иммунитеты. Также Конвенция по своей сути представляет собой образец того, какие иммунитеты в последствии могут включить специализированные учреждения в свои учредительные акты.

Конвенция состоит из стандартных статей об иммунитетах и дополнений, касающихся каждого из специализированных учреждений. Стандартные статьи посвящаются правовому статусу международных организаций, их иммунитету в отношении имущества, фондов и активов, иммунитету в отношении средств связи, иммунитету представителей членов специализированных учреждений, иммунитету должностных лиц и др.

Особое внимание стоит уделить девятой статье Конвенции, посвященной порядку разрешения споров. Согласно данной статье, каждое специализированное учреждение должно устанавливать свои положения о способах разрешения споров, вытекающих из коммерческих договоров, стороной в которых является само учреждение, и иных споров частноправового характера, а также споров в отношении должностных лиц специализированных учреждений, обладающих иммунитетом. Однако, в рассмотренных ранее Статьях Соглашения Международного валютного фонда, положения, касающиеся рассмотрения подобных споров сводятся к тому, что данные организации обладают абсолютным иммунитетом, а рассмотрение указанных споров возможно только в случае согласия самой организации или если это прописано в соответствующем контракте.

Дополнения 5 и 6 Конвенции, посвященные соответственно Международному валютному фонду и Международному банку реконструкции и развития, расширяют по сравнению со стандартными положениями иммунитеты указанных организаций в отношении налогов, сборов и иных обязательных платежей, а также конкретизируют некоторые вопросы судебного иммунитета. Эти положения практически полностью были интерпретированы в учредительные акты указанных организаций.

Таким образом, рассмотрев нормативное закрепление иммунитетов международных финансовых организаций в их учредительных актах, можно сделать вывод, что в целом, структура их закрепления, а также основные положения совпадают между собой, а также во многом дублируют положения Конвенции ООН о привилегиях и иммунитетах специализированных учреждений и других.

Во многом правовая природа иммунитетов международных финансовых организаций имеет сходства с концепцией абсолютного иммунитета государств, хотя эти понятия и опираются на разные основания. Такой «абсолютный» иммунитет международных финансовых организаций, осуществляющих частноправовую деятельность, нарушает права их частных контрагентов и ставит последних в неблагоприятное положение. Решением данной проблемы в современных условиях является институт отказа от иммунитетов международными финансовыми организациями. Возможным оптимальным решением может стать установление обязанности международных финансовых организаций отказываться от судебного иммунитета по определенным категориям дел, посредством закрепления такой обязанности в международных договорах.

Наличие иммунитета у международных финансовых организаций, как уже отмечалось, существенно затрудняет производство в национальных судах. Абсолютный характер судебных иммунитетов международных организаций требует их согласия или особого на то указания в договорах, чтобы привлечь организацию к участию в судебном процессе. Поэтому в подавляющем большинстве случаев, когда иски в национальные суды предъявляются к международным организациям, производство по таким делам просто прекращается со ссылкой на наличие у ответчика иммунитета. Однако при этом, сама международная организация, опираясь на положения о ее правовом статусе, закрепленном в ее учредительных документах, вправе инициировать судебное производство. Такая ситуация ставит в неравное положение сторон процесса, чем нарушает принципы равноправия сторон и состязательности процесса. Чтобы избежать подобных проблем, необходимо, чтобы в определенных случаях судебный иммунитет международных финансовых организаций каким-либо образом ограничивался.

Наиболее простым способом ограничения иммунитета международной финансовой организации является ее самостоятельный отказ от иммунитета. В.В. Афанасьев, например, рассматривает данное право международной организации как «единственный правомерный способ административного или судебного разрешения споров в случае предъявления гражданско-правовых требований».

Возможность организации отказаться от иммунитета прямо предусматривается в учредительных актах многих международных финансовых организаций. Например, как уже отмечалось, такое право отдельно закреплено в учредительных актах Международной финансовой корпорации и Многостороннего агентства по гарантиям инвестиций. Кроме того, право на отказ от судебного иммунитета закрепляется также в Конвенции о привилегиях и иммунитетах специализированных учреждений (раздел 4). Так, можно говорить о том, что 
право на отказ от иммунитета в том или ином виде предоставляется всем международным организациям.

По своей правовой природе отказ международной организации от иммунитета, является ее правом, а не обязанностью, о чем свидетельствуют нормативные акты, в которых такие отказы закреплены. Между тем, в некоторых случаях появляется необходимость закрепления именно обязанности международной организации отказаться от иммунитета. Так, например, в спорах, связанных с возмещением вреда, причиненного международной организацией жизни и здоровью граждан, объективно необходим обязательный отказ международной организации от иммунитета. Такая обязанность международных организаций обеспечила бы упрощение процедуры восстановления нарушенных прав граждан.

При этом в некоторых соглашениях о привилегиях и иммунитетах международных финансовых организаций с государствами все же предусматривается обязанность таких организаций отказываться от иммунитетов, но только в отношении своих должностных лиц. Например, в Соглашении между Правительством РФ и Европейским банком реконструкции и развития в разделе 43 статьи 14 указывается, что в случае, если должностные лица используют предоставленные им привилегии, иммунитеты и иные льготы в целях личной выгоды, Банк обязан отказаться от иммунитета, предоставленного таким лицам, если, по его мнению, такой иммунитет препятствует осуществлению правосудия и отказ от него не наносит ущерба целям, для которых иммунитеты предоставлены [8]. Аналогичные положения содержатся в Соглашении между Правительством РФ и Международным валютным фондом (раздел 7 статьи 9) [9]. Думается, что разумно было бы аналогичным образом решать вопрос об отказе от привилегий и иммунитетов самих международных финансовых организациях.

Вообще сущность судебного иммунитета международных финансовых организаций сводится к тому, что он позволяет организациям беспрепятственно осуществлять предусмотренные ее учредительными документами функции, без вмешательства со стороны государств и иных лиц. Но помимо таких функций для обеспечения своей жизнедеятельности или в иных целях, международная финансовая организация может осуществлять не предусмотренную учредительными документами коммерческую деятельность частноправового характера. По своей сути, судебный иммунитет не должен распространяться на споры с международными организациями по поводу такой деятельности. Но на практике зачастую международные организации пользуются судебным иммунитетом вне зависимости от предмета спора, что по своей природе является злоупотреблени- ем данным правом, которое в теории может стать причиной ограничения иммунитета при рассмотрении финансовых споров с участием международных финансовых организаций.

Появление злоупотребления правом на судебный иммунитет во многом связано с тем, что в нормативных актах, посвященных иммунитетам международных организаций, не дается четких границ данного права, в силу чего, оно трактуется слишком широко. Для того, чтобы избежать чересчур широкой трактовки судебных иммунитетов необходимо установление границ действия данного права. Во многом, установив целевое назначение предоставленного международной организации права на судебный иммунитет, можно определить, присутствует ли в конкретном деле злоупотребление со стороны международной организации своим правом на иммунитет.

Такую позицию поддерживает и судебная практика. Так, Информационное письмо Президиума Высшего арбитражного суда РФ от 18.01.2001 № 58, предусматривает, что судебный иммунитет международной организации не распространяется на ее коммерческую деятельность, не предусмотренную соответствующим международным договором (ее уставом или соглашением о штаб - квартире). Как пример, можно привести дело, рассмотренное в нескольких инстанциях московскими арбитражными судами. Международный инвестиционный банк сдавал помещения на территории РФ в аренду и получал от этого определенную прибыль, на которую налоговые органы РФ начислили соответствующий налог. Тогда Банк, ссылаясь на наличие у него иммунитета, в том числе иммунитета от налогов и иных обязательных платежей, подал иск в суд, о признании решения налогового органа неправомерным. В итоговом решении по делу суд признал решение налогового органа правомерным, поскольку исходя из учредительных документов Банка, получение прибыли от сдачи имущества в аренду не является функцией Банка и не способствует достижению его уставных целей, а также обязал Банк уплатить соответствующий налог [10].

Исходя из этого, применение судом принципа осуществления права в соответствии с его назначением в целях избежания злоупотребления правом, можно выделить как один из способов ограничения иммунитетов международных финансовых организаций при рассмотрении споров с их участием в национальных судах.

Что касается российского законодательства, то в нем вопросы ограничения иммунитетов международных финансовых организаций не получили детального нормативного закрепления. Так, порядок разрешения дел с участием международных организаций, обладающих 
судебным иммунитетом, закреплен в Арбитражном процессуальном кодексе [11] и Гражданском процессуальном кодексе [12]. Согласно статьям 251 и 401 соответственно, судебные иммунитеты международных организаций определяются международными договорами РФ и федеральными законами, а отказ международной организации от иммунитета осуществляется по внутренним правилам организации. То есть, по сути, ограничение иммунитета международной организации возможно только в виде ее отказа от иммунитета. При этом, Постановление Пленума Высшего арбитражного суда РФ от 11.06.1999 № 8, конкретизирует порядок отказа международной организации от иммунитета и устанавливает форму такого отказа [13]. Согласно данному постановлению, арбитражный суд может принять иск к международной организации к рассмотрению только при наличии явно выраженного согласия этой организации. Такое согласие должно быть подписано лицами, уполномоченными на отказ от судебного иммунитета внутренними правилами международной организации.

Если обращаться к судебной практике российских судов по рассмотрению дел с участием международных финансовых организаций, то можно заметить, что с учетом того, что количество таких дел итак небольшое, лишь в единичных случаях дела рассматриваются в силу какого-либо способа ограничения иммунитетов международных финансовых организаций. Большинство же дел с участием международных финансовых организаций, рассматриваемых российскими судами, прекращаются со ссылкой на наличие у такой организации иммунитета. Так, например, Арбитражный суд города Москвы в 2012 году рассматривал дело по иску компании «ЧизПартнерз Холланд В.О.Ф.» к Европейскому банку реконструкции и развития и компании «Рофаэр Девелопментс Лимитед» о взыскании денежных средств. В решении суда по данному делу в отношении Европейского банка реконструкции и развития даже не рассматривались фактические обстоятельства, поскольку Банк сразу заявил о наличии у него судебного иммунитета. Поэтому суд со ссылкой на Соглашение между Правительством РФ и Европейским банком реконструкции и развития о постоянном представительстве Банка (как на документ, определяющий наличие судебного иммунитета), а также на Соглашение об учреждении Европейского банка реконструкции и развития (как на документ, определяющий порядок отказа Банка от иммунитета) прекратил производство по делу в отношении Европейского банка реконструкции и развития. В дальнейшем дело рассматривалось в апелляционной и кассационной инстанциях, но решение суда так и не изменилось.

Другим примером может являться рассмотренное в 2017 году Арбитражным судом Красноярского края дело по иску акционерного общества «Лесосибирский лесоперевалочный комбинат» к Евразийскому банку развития о взыскании задолженности. Истец утверждал, что ответчик не может воспользоваться правом на судебный иммунитет, поскольку заключенный между ними договор носит коммерческий частноправовой характер. В своем определении по данному делу со ссылкой на Соглашение об учреждении Евразийского банка развития, включающее также Устав Банка, суд пришел к выводу, что заключенный между сторонами договор полностью соответствует уставным целям Банка, а следовательно, Банк может воспользоваться правом на судебный иммунитет. Поэтому дело было прекращено.

Таким образом, иммунитеты международных финансовых организаций являются функциональными, то есть необходимы для обеспечения беспрепятственной реализации предусмотренных учредительными документами организации функций, поэтому они не должны распространяться на иную деятельность такой организации, а, следовательно, должны ограничиваться путем отказа международной финансовой организации от иммунитета или путем признания судом злоупотребления правом со стороны такой организации.

Следует отметить, что существующие сегодня международные финансовые организации имеют штат сотрудников, являющихся гражданами различных государств. Как и в любых национальных, в международных организациях нередко возникают трудовые споры. Вопрос о том, какие судебные учреждения обладают компетенцией по разрешению подобных споров, долгое время оставался нерешенным. Во-первых, сотрудники международных организаций являются частными лицами, поэтому юрисдикция международных судов на споры с их участием, как правило, не распространяется. Во-вторых, международные финансовые организации обладают судебными иммунитетами, соответственно, в национальных судах такие споры тоже не могут быть разрешены. Кроме того, трудовые отношения с сотрудниками международных организаций не подчиняются какому-либо национальному трудовому законодательству, а регулируются внутренним правом международных организаций, поэтому юрисдикция международных и национальных судов не может на них распространяться.

В связи с этим, нередко получалось так, что при нарушении трудовых прав работников международных финансовых организаций, складывалась ситуация, когда кроме как обращения в исполнительные органы международной организации, обжаловать такие правонарушения было негде. Подобные обращения, как правило, приводили к результату не в пользу работников, поскольку, по сути, нарушающие права сотрудников решения принимали те же лица, которые впоследствии разрешали возникающие споры. Такая ситуация существует 
до сих пор в связи с тем, что по сути, международные финансовые организации обладают абсолютным иммунитетом в отношении данной категории споров.

Решением данной проблемы стало образование специальных независимых органов внутри международных финансовых организаций - административных трибуналов, которые наделены компетенцией по разрешению всех трудовых споров с сотрудниками конкретной организации. В настоящий момент, такие трибуналы являются единственными органами, обладающими подобной компетенцией, поэтому выносимые ими решения являются окончательными и неподлежащими обжалованию.

Со временем административные трибуналы появились в подавляющем большинстве международных финансовых организаций. Постепенно они стали полноценными судебными органами со своей особой юрисдикцией. По общему правилу административные трибуналы обладают юрисдикцией на разрешение споров только внутри организаций, в рамках которых они созданы. Как правило, такие трибуналы разрешают небольшое количество дел, так как спорные ситуации возникают относительно не часто. Многие крупные организации, такие как Организация Объединенных Наций или Международная организация труда, создавая свои Трибуналы, предусматривают в их учредительных документах возможность для других организаций присоединиться к юрисдикции своих Трибуналов.

Административный трибунал Международного валютного фонда, как и все другие трибуналы, по общему правилу обладает юрисдикцией на разрешение внутренних споров. Согласно второй статье своего Устава, Трибунал обладает юрисдикцией в отношении любого заявления члена персонала Фонда, в котором такой член оспаривает законность административного акта, нарушающего каким-либо образом его права. При этом под административным актом понимается любое индивидуальное или нормативное решение, принятое органами управления Фонда в отношении его персонала. Комментируя данное положение, можно сделать вывод, что трибунал, как орган, осуществляющий функции суда, будет определять факт наличия нарушения норм применяемого Фондом внутреннего права при принятии конкретного управленческого решения. При этом, из смысла содержания статьи прямо вытекает то, что для решения Трибуналом вопроса о законности того или иного административного акта, необходимо, чтобы этот акт оказал реальное неблагоприятное воздействие на обратившегося с заявлением сотрудника. То есть, Административный трибунал не будет разрешать вопросы гипотетического характера или выносить заключения в виде консультаций.
В положениях той же второй статьи говорится о том, что в юрисдикцию Трибунала входит также разрешение споров, связанных с пенсионным или иным социальным обеспечением сотрудников Фонда. К таким спорам относятся споры о так называемых Планах пенсионного обеспечения персонала, Планах предоставления медицинских льгот и Планах страхования жизни сотрудников. Благодаря этой норме расширяется круг субъектов, имеющих право обращаться в Трибунал. Например, если это дело об обжаловании решений, связанных с предоставлением пенсионного обеспечения, то в Трибунал могут обращаться с жалобами и бывшие сотрудники Фонда, вышедшие на пенсию. Или если это дело об обжаловании решений, связанных с выплатой страховых компенсаций в случае смерти сотрудника Фонда, то в Трибунал могут обращаться все выгодоприобретатели по данным компенсациям (как правило, родственники сотрудника).

Кроме юрисдикции в отношении самого Фонда, Административный трибунал, согласно статье 21 своего Статута, может обладать юрисдикцией в отношении любой другой международной организации в случае, если с ней составлено специальное соглашение [14]. В таком соглашении должно предусматриваться, что решения Административного трибунала МВФ будут обязательны для такой организации, и она будет нести ответственность за выплату каких-либо компенсаций, присужденных Трибуналом в отношении сотрудников этой организации и иных лиц. Также в соглашении должно быть указано, что такая организация будет содействовать функционированию Трибунала, в том числе, посредством участия в некоторых расходах Трибунала. Однако при этом присоединившаяся к юрисдикции Трибунала международная организация не будет иметь полномочий по назначению членов Трибунала, а также полномочий по внесению изменений в Устав Трибунала.

Юрисдикция Административного трибунала Всемирного банка несколько отличается от юрисдикции Административного трибунала Международного валютного фонда. Всемирный банк изначально действует как группа организаций, поэтому и юрисдикция его Административного трибунала распространяется на каждую из входящих в его группу организаций. Так, согласно первой статье своего Статута, Трибунал учреждается в рамках Международного банка реконструкции и развития, Международной ассоциации развития, а также Международной финансовой корпорации. Из этого следует, что внутренняя юрисдикция Административного трибунала Всемирного банка будет распространяться на сотрудников каждой из перечисленных организаций.

Исходя из положений второй статьи Статута, Трибунал обладает юрисдикцией в отношении любых споров по заявлениям персонала, связанным с трудовыми дого- 
ворами и соответствующими условиями работы. Также к юрисдикции Трибунала относятся все споры, вытекающие из отношений по пенсионному и иному социальному обеспечению, поэтому, как и в случае с Административным трибуналом Международного валютного фонда, в круг субъектов, которые могут подавать заявления в Трибунал, включаются бывшие сотрудники Банка, а также иные, связанные с сотрудниками лица.

Говоря о юрисдикции Административного трибунала Всемирного банка в отношении других организаций, можно обратиться к положению статьи 15 Статута Трибунала, согласно которой Банк может заключить соглашение с другой международной организацией, в соответствии с которым на саму организацию и на ее сотрудников будут распространяться полномочия его Административного трибунала. Соглашение должно будет предусматривать, что такая организация будет принимать решения Трибунала Всемирного банка, как окончательные и обязательные к исполнению, а также нести ответственность по выплате компенсаций в случае, если Трибунал присудит их сотруднику или иному лицу в результате разрешения спора. В соглашении также указывается, что такая организация принимает участие в обеспечении деятельности Трибунала соответствующими административными мерами, а также его финансированием.

На основе этого, можно сделать вывод, что в целом юрисдикции Административного трибунала Международного валютного фонда и Административного трибунала Всемирного банка почти не имеют существенных отличий. Оба трибунала имеют юрисдикционные полномочия в отношении своих сотрудников (а также бывших сотрудников и лиц, вступающих в правоотношения с организацией как выгодоприобретатели), что является стандартным принципом распределения юрисдикции административных трибуналов. В рамках этого вида юрисдикции решаются все дела указанных административных трибуналов. Каждый из двух рассматриваемых трибуналов кроме того может обладать юрисдикцией и в отношении иных международных организаций при наличии специальных соглашений. Однако, на настоящий момент таких соглашений не зафиксировано ни в рамках Международного валютного фонда, ни в рамках Всемирного банка, поэтому реальной практики разрешения дел в рамках этого вида юрисдикции у указанных административных трибуналов нет.

Таким образом, рассмотрев практику разрешения трудовых споров в международных финансовых организациях, можно сделать вывод, что в настоящее время единственным доступным способом является разрешение таких споров в рамках административных трибуналов, создаваемых внутри таких организаций. Только административные трибуналы обладают необходимой юрисдикцией по решению споров международных финансовых организаций со своими сотрудниками, что свидетельствует об абсолютном иммунитете организаций в данном вопросе.

Анализируя рассмотренные положения об иммунитетах в целом, можно сделать вывод, что реализация ответственности международных финансовых организаций в рамках национальных правовых систем либо очень затруднена, либо в принципе невозможна, как, например, в случае с трудовыми спорами. Во-первых, это объясняется особым правовым статусом международных финансовых организаций, как субъектов международного публичного права. Во-вторых, это связано с тем, что даже в частноправовых отношениях такие организации рассматриваются как публичные субъекты с особым статусом, не позволяющим реализовывать нормы об ответственности. И в-третьих, нормативное закрепление иммунитетов международных финансовых организаций пока является слишком широким, нередко позволяющим использовать иммунитеты в своих целях.

\section{ЛИТЕРАТУРА}

1. Суменков С. Ю. Привилегии и иммунитеты как общеправовые категории: дис... канд. юрид. наук. 2002. С. 130.

2. Статьи Соглашения Международного Валютного Фонда (приняты 22.07.1944). URL: https://www.imf.org/external/pubs/ft/aa/rus/index.pdf.

3. Статьи Соглашения Международного Банка Реконструкции и Развития (Приняты в г. Вашингтоне 27.12.1945) // Международное частное право. Сборник документов.-М.: БЕК, 1997. С. 74-93.

4. Статьи Соглашения Международной финансовой корпорации 1956 г.URL: https://www.ifc.org/wps/wcm/connect/00639891-7c2e-4bff-8bb3-182c074d17e4/ Articles_of_Agreement_Russian.pdf? MOD=AJPERES\&CVID=jJSoizw.

5. Сеульская конвенция 1985 года об учреждении Многостороннего агентства по гарантиям инвестиций URL: https://www.miga.org/sites/default/files/ archive/Documents/MIGA\%20Convention\%20February\%202016.pdf.

6. Конвенция об урегулировании инвестиционных споров между государствами и физическими или юридическими лицами других государств (Вашингтон, 18 марта 1965 г.). URL: http://icsidfiles.worldbank.org/ICSID/ICSID/StaticFiles/basicdoc/partA.htm.

7. Конвенция 00Н от 21 ноября 1947 г. о привилегиях и иммунитетах специализированных учреждений. URL: https://www.un.org/ru/documents/decl_conv/ conventions/specagencies_privileges.shtml. 
8. «Соглашение между Правительством Российской Федерации и Европейским банком реконструкции и развития о Постоянном представительстве Европейского банка реконструкции и развития» (Заключено в г. Москве 29.03.1993) // Бюллетень международных договоров. 2010. № 5. С. 10-18.

9. «Соглашение между Правительством Российской Федерации и Международным валютным фондом о Постоянном представительстве Международного валютного фонда в Российской Федерации» (Заключено в г. Гонконге 24.09.1997) // СЗ РФ. 12 сентября 2005 г. № 37. С. 3734.

10. Постановление Арбитражного суда Московского округа от 29.09.2005 по делу № A40-65100/04-90-685 // URL: https://kad.arbitr.ru/

11. «Арбитражный процессуальный кодекс Российской Федерации» от 24.07.2002 № 95-Ф3 (ред. от 02.12.2019) // С3 РФ. 29.07.2002. № 30. ст. 3012.

12. «Гражданский процессуальный кодекс Российской Федерации» от 14.11.2002 № 138-Ф3 (ред. от 02.12.2019) // С3 РФ. 18.11.2002. № 46. ст. 4532.

13. Постановление Пленума Высшего арбитражного суда Российской Федерации от 11.06.1999 № 8 «0 действии международных договоров Российской Федерации применительно к вопросам арбитражного процесса» // «Вестнике Высшего Арбитражного Суда Российской Федерации». 1999 г. № 8.

14. Статут Административного трибунала Международного валютного фонда, 1992 г. URL: https://www.imf.org/external/imfat/statute.htm.

( ) Чувахин Петр Игоревич ( chuvakhin.petr@yandex.ru ).

Журнал «Современная наука: актуальные проблемы теории и практики»

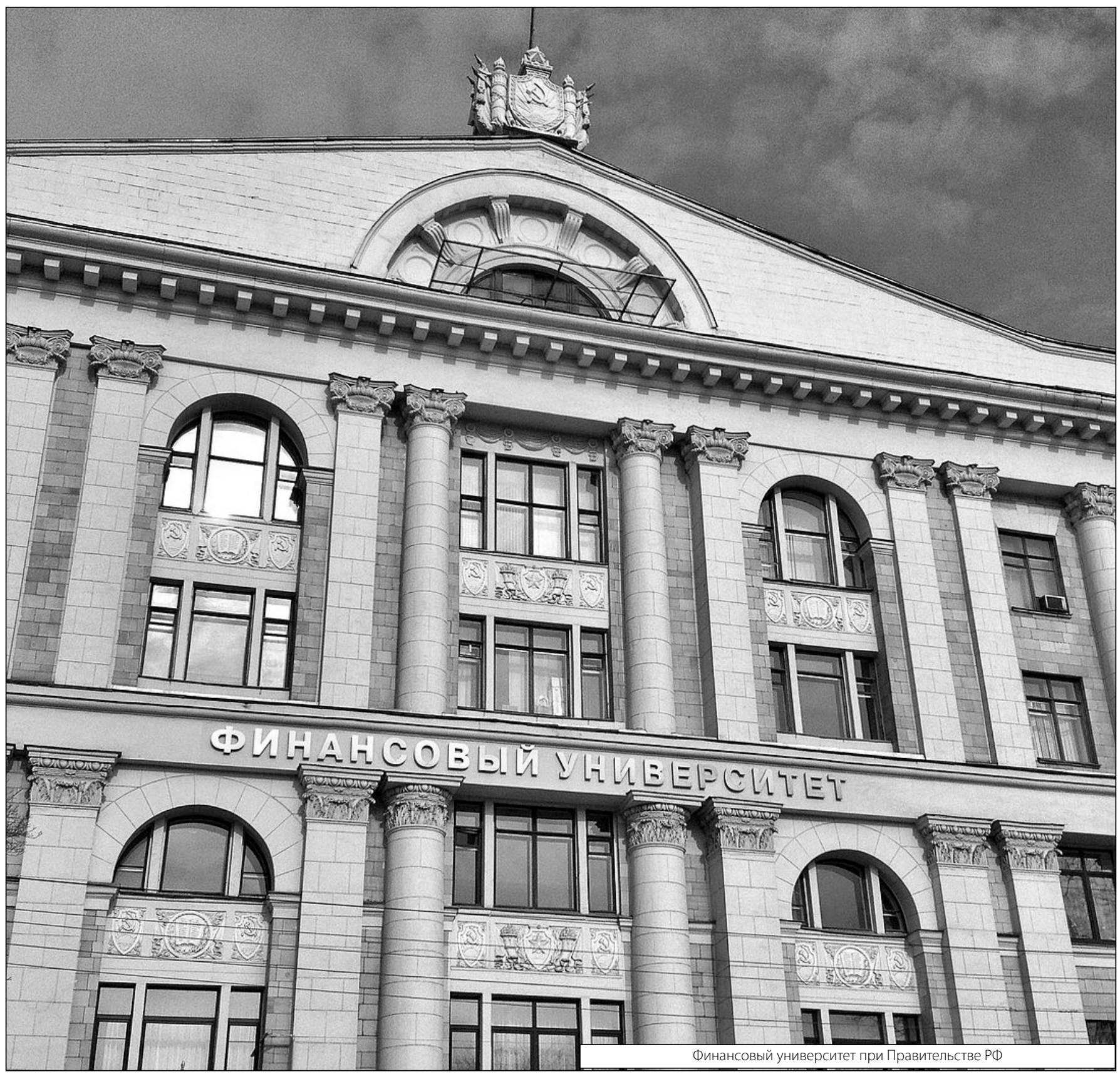

